\title{
HUBUNGAN LINGKAR LENGAN ATAS IBU HAMIL DENGAN BERAT BADAN LAHIR BAYI DI RUMAH SAKIT UMUM CUT MEUTIA KABUPATEN ACEH UTARA DAN RUMAH SAKIT Tk IV IM.07.01 LHOKSEUMAWE TAHUN 2015
}

\author{
Ayu Rahma Putri ${ }^{1}$, Al Muqsith ${ }^{2 *}$ \\ ${ }^{1}$ Mahasiswa Fakultas Kedokteran Universitas Malikussaleh \\ 2Bagian Anatomi Fakultas Kedokteran Universitas Malikussaleh \\ Lhokseumawe-Aceh 24352, Indonesia \\ *Corresponding Author:al_muqsith2317@yahoo.co.id
}

\begin{abstract}
Abstrak
Berat badan adalah indikator kesehatan bayi baru lahir. Berat badan lahir bayi dipengaruhi oleh status gizi ibu. Status gizi ibu hamil dapat diketahui melalui pengukuran lingkar lengan atas (LILA). Penelitian ini bertujuan untuk mengetahui hubungan lingkar lengan atas ibu hamil dengan berat badan lahir bayi di Rumah Sakit Umum Cut Meutia Kabupaten Aceh Utara dan Rumah Sakit Tk IV IM.07.01 Lhokseumawe tahun 2015. Penelitian ini merupakan penelitian analitik denganrancangan cross sectional, pengambilan sampel dilakukan secara consecutive sampling. Jumlah sampel sebanyak 85 responden yaitu ibu hamil yang melahirkan di Rumah Sakit Umum Cut Meutia Kabupaten Aceh Utara dan Rumah Sakit Tk IV IM.07.01 Lhokseumawe. Data penelitian diambil dari data primer yaitu data demografi ibu hamil, pengukuran LILA ibu hamil dan berat badan lahir bayi. Analisis data menggunakan uji Chi-square dan convidence interval (95\%) dengan derajat kemaknaan 0,05. Hasil penelitian ini menunjukkan bahwa ibu hamil yang memiliki ukuran LILA normal sebanyak 78 orang $(91,8 \%)$ dan 7 orang $(8,2 \%)$ ibu yang memiliki LILA $<23,5 \mathrm{~cm}$ atau berisiko KEK. Sebagian besar berat badan lahir bayi adalah kategori berat lahir normal sebanyak 74 bayi $(87,1 \%)$. Kategori bayi berat lahir rendah (BBLR) sebanyak 8 bayi $(9,4 \%)$. Ada hubungan antara lingkar lengan atas ibu hamil dengan berat badan lahir bayi (nilai signifikansi $\mathrm{p}=0,006)$.
\end{abstract}

Kata Kunci: Lingkar lengan atas; berat badan lahir bayi; ibu hamil 


\title{
THE RELATIONSHIP BETWEEN THE MID UPPER ARM CIRCUMFERENCE OF PREGNANT WOMEN WITH THE INFANT'S BIRTH WEIGHT IN THE CUT MEUTIA GENERAL HOSPITAL IN NORTH ACEH REGENCY AND TK IV IM.07.01 HOSPITAL IN LHOKSEUMAWE IN 2015
}

\begin{abstract}
Birth weight is an indicator of the health of newborn. Infant's birth weight is influenced by the mother's nutritional status. The nutritional status of pregnant women can be revealed through measurement of the mid upper arm circumference (MUAC). This study aims to determine the relationship between the mid upper arm circumference of pregnant women with the infant's birth weight in the Cut Meutia General Hospital in North Aceh Regency and Tk IV IM.07.01 Hospital in Lhokseumawe in 2015. This analytical research used cross sectional design, sampling was carried out by using consecutive sampling. The number of sample are 85 respondents including pregnant women who gave birth in Cut Meutia General Hospital North Aceh Regency and in Tk IV IM.07.01 Hospital in Lhokseumawe. The data of this study derived from the primary data, such as identities data of pregnant women, MUAC measurements and infant's birth weight. Data analysis using Chi-square test and convidence interval (95\%) with a significance level 0.05 . The results of this study indicate that pregnant women with normal MUAC counted 78 persons $(91.8 \%$ ) and less $23,5 \mathrm{~cm}$ as much as 7 persons $(8.2 \%)$. Most of infant's birth weight are normal birth weight category as much as 74 infants $(87.1 \%)$. Low birth weight (LBW) infant categories as much as 8 infants $(9.4 \%)$. There is a relationship between the circumference of the mid upper arm of pregnant women with infant's birth weight (significant value $\mathrm{p}=$ 0.006).
\end{abstract}

Keywords: The mid upper arm circumference; infant's birth weight; pregnant women 


\section{Pendahuluan}

Berat badan adalah suatu indikator kesehatan bayi baru lahir. Berat badan bayi baru lahir ditentukan oleh status gizi janin. Status gizi janin ditentukan antara lain oleh status gizi ibu waktu konsepsi dan dipengaruhi pula oleh status gizi ibu pada waktu melahirkan. Status gizi ibu sewaktu konsepsi dipengaruhi oleh keadaan sosial dan ekonomi ibu sebelum hamil, keadaan kesehatan, jarak kehamilan, multiparitas dan usia kehamilan. Status gizi bayi yang dilahirkan ibu akan baik, jika keadaan kesehatan dan gizi ibu baik, begitu pula sebaliknya. $^{1}$

Status gizi ibu di Indonesia menjadi masalah penting karena masih tingginya berbagai keadaan kurang gizi. Banyak penelitian membuktikan bahwa untuk memperbaiki suatu hasil outcome kehamilan, misalnya berat badan lahir, intervensi melalui perbaikan status gizi ibu sebelum kehamilannya lebih efektif daripada suplementasi selama kehamilannya. Program perbaikan gizi sebaiknya telah dimulai sebelum kehamilan, termasuk meningkatkan asupan mikronutrien dan meningkatkan berat badan sebelum kehamilan. ${ }^{2}$ Masa kehamilan adalah masa seorang wanita memerlukan berbagai unsur gizi yang jauh lebih banyak daripada yang diperlukan dalam keadaan biasa. Perubahan anatomi, fisiologis dan biokimia pada ibu mempunyai dampak besar terhadap diet ibu dan kebutuhan nutrisinya. Perubahan itu berguna untuk mengatur metabolisme ibu, mendukung pertumbuhan janin, persiapan ibu untuk melahirkan, kelahiran, dan menyusui. ${ }^{1}$

Status gizi ibu hamil dapat diketahui dengan mengukur ukuran lingkar lengan atas (LILA), bila kurang dari 23,5 cm maka ibu hamil tersebut termasuk kurang energi kronis (KEK), sehingga ibu hamil tersebut dapat berisiko melahirkan bayi berat lahir rendah (BBLR). ${ }^{3}$ Dibandingkan dengan indikator antropometri lainnya, LILA paling praktis penggunaannya di lapangan, dapat disiapkan secara mudah dengan dana yang tidak mahal serta tidak membutuhkan pelatihan intensif dalam keterampilan menggunakannya. ${ }^{4}$

Ibu penderita malnutrisi sepanjang minggu terakhir kehamilan akan melahirkan BBLR (<2500 gr) karena jaringan lemak banyak ditimbun selama trimester III. Bayi berat lahir rendah (BBLR) merupakan masalah penting dalam pengelolaannya karena mempunyai kecenderungan ke arah peningkatan terjadinya infeksi dan kesulitan pernapasan sehingga mudah untuk menderita hipotermia. Bayi berat lahir rendah mudah terserang komplikasi tertentu seperti ikterus, hipoglikemia yang dapat menyebabkan kematian. ${ }^{4}$ Kelompok BBLR diistilahkan dengan kelompok risiko tinggi, karena pada BBLR menunjukkan angka kematian dan kesakitan neonatal yang lebih tinggi dibanding bayi berat lahir normal. ${ }^{5}$

Hasil Riskesdas tahun 2013 menunjukkan bahwa prevalensi risiko KEK pada wanita hamil umur 15 sampai 49 tahun secara nasional sebanyak 24,2\%. Jumlah ibu hamil di Aceh tahun 2013 sebanyak 110.644 dan prevalensi KEK wanita hamil di Aceh tahun 2013 adalah sebanyak 20\%. Prevalensi risiko KEK wanita usia subur (WUS) umur 15 sampai 49 tahun secara nasional tahun 2013 sebanyak 20,8\%. Aceh termasuk salah satu provinsi dengan risiko KEK pada WUS di atas nasional yaitu sebanyak $25 \%$. $^{6}$

Berdasarkan data dari Dinas Kesehatan Aceh Utara tahun 2014 menunjukkan bahwa jumlah kematian neonatal meningkat dari tahun 2013sebanyak 74 neonatal menjadi 94 neonatal pada tahun 2014. Mayoritas peningkatan kematian neonatal terjadi akibat BBLR sebanyak 28 neonatal tahun 2013 menjadi 43 neonatal pada tahun 2014 (Dinkes Aceh Utara, 2014). ${ }^{7}$ Hasil data akumulasi per tahun Dinas Kesehatan kota 
Lhokseumawe tahun 2013, terdapat 23 kematian neonatal. Penyebab kematian neonatal di antaranya; akibat BBLR sebanyak 10 neonatal, asfiksia sebanyak 10 neonatal dan 3 kematian neonatal akibat infeksi dan lain-lain. ${ }^{8}$

Data dari ruang nifas Rumah Sakit Cut Meutia tahun 2013 terdapat sebanyak 91 bayi dengan BBLR (<2500 gr) dan 15 di antaranya mengalami kematian. Data kunjungan ibu hamil trimester III dari bulan Januari sampai dengan April 2014 terdapat sebanyak 114 orang. Data dari ruang nifas Rumah Sakit Tk IV IM.07.01 Lhokseumawe tahun 2013 terdapat sebanyak 27 bayi dengan BBLR.

\section{Metode Penelitian}

Penelitian ini merupakan penelitian analitik dengan rancangan potong lintang (cross sectional study). Populasi dalam penelitian ini adalah seluruh ibu hamil yang melahirkan di Rumah Sakit Umum Cut Meutia yang berjumlah 494 ibu bersalin pada tahun 2013 dan seluruh ibu hamil yang melahirkan di Rumah Sakit Tk IV IM.07.01 Lhokseumawe yang berjumlah $243 \mathrm{ibu}$ bersalin tahun 2013.
Sampel yang diambil adalah ibu hamil yang memenuhi kriteria inklusi berupa ibu hamil yang akan melahirkan dengan usia kehamilan 37 - 40 minggu, bayi lahir hidup, cara persalinan pervaginam atau sectio caesarea, serta kriteria eksklusi berupa ibu dengan kehamilan ganda atau kembar dan ibu yang menderita penyakit kronis (diabetes, hipertensi, jantung dan asma). Besar sampel yang dibutuhkan dalam penelitian ini minimal $85 \mathrm{ibu}$ hamil trimester III yang akan melakukan persalinan di Rumah Sakit Umum Cut Meutia dan Rumah Sakit Tk IV IM.07.01 Lhokseumawe. Sampel diambil menggunakan metode nonprobability sampling yaitu consecutive sampling. Sumber data berasal dari data primer, berupa identitas ibu menggunakan kuesioner, pengukuran lingkar lengan atas menggunakan pita LILA dan penimbangan berat badan lahir bayi.

\section{Hasil Penelitian}

Berdasarkan ukuran lingkar lengan atas (LILA), sebagian besar ibu hamil mempunyai LILA normal $(>23,5 \mathrm{~cm})$ yaitu sebanyak 78 orang $(91,8 \%)$, dan hanya 7 orang $(8,2 \%)$ ibu yang mempunyai LILA $<23,5 \mathrm{~cm}$ atau yang risiko KEK (tabel 5.1).

Tabel 5.1 Distribusi Frekuensi Ibu Berdasarkan Lingkar Lengan Atas di Rumah Sakit Umum Cut meutia Kabupaten Aceh Utara dan Rumah Sakit Tk IV IM.07.01 Lhokseumawe Tahun 2015

\begin{tabular}{lcc}
\multicolumn{1}{c}{ LILA Ibu } & Frekuensi & Persentase $(\%)$ \\
\hline Bukan risiko KEK $(\geq 23,5 \mathrm{~cm})$ & 78 & 91,8 \\
Risiko KEK $(<23,5 \mathrm{~cm})$ & 7 & 8,2 \\
\hline Total & 85 & 100 \\
\hline
\end{tabular}

Sumber: Data primer, 2015

Pada penelitian ini diperoleh bahwa sebagian besar bayi yang dilahirkan berada pada kategori bayi berat lahir normal, yaitu sebanyak 74 bayi $(87,1 \%)$. Kategori bayi berat lahir rendah (BBLR) sebanyak 8 bayi $(9,4 \%)$ dan hanya 3 bayi $(3,5 \%)$ berada pada kategori berat bayi lahir lebih (tabel 5.2). 
Tabel 5.2 Distribusi Frekuensi Berat Badan Bayi Lahir di Rumah Sakit Umum Cut meutia Kabupaten Aceh Utara dan Rumah Sakit Tk IV IM.07.01 Lhokseumawe Tahun 2015

\begin{tabular}{lcc}
\hline \multicolumn{1}{c}{ LILA Ibu } & Frekuensi & Persentase $(\%)$ \\
\hline BBLR (<2500 gram) & 8 & 9,4 \\
Normal (2500-4000 gram) & 74 & 87,1 \\
Lebih (>4000 gram) & 3 & 3,5 \\
\hline Total & 85 & 100 \\
\hline Sumber: Data primer, 2015 & &
\end{tabular}

Berdasarkan hasil tabel silang (cross tabulation), menunjukkan bahwa dari $78 \mathrm{ibu}$ hamil yang bukan risiko KEK (LILA >23,5 $\mathrm{cm})$, sebagian besar melahirkan bayi berat lahir normal yaitu sebanyak 70 ibu $(89,7 \%)$, dan hanya $5 \mathrm{ibu}(6,4 \%)$ yang melahirkan bayi berat lahir rendah (BBLR). Dari 7 ibu hamil berisiko KEK (LILA $<23,5 \mathrm{~cm}$ ), sebanyak 3 orang $(42,9 \%)$ ibu melahirkan bayi BBLR dan 4 orang $(57,1 \%)$ ibu melahirkan bayi berat lahir normal (tabel 5.3). Hasil analisis bivariat hubungan lingkar lengan atasibu hamil dengan berat badan lahir bayi menggunakan uji statistik Chi-Square dan convidende interval 95\% (derajat kemaknaan 0,05 ) dan diperoleh nilai pvalue $=0,006 \quad(p$ value $<0,05)$. Hal ini menunjukkan bahwa Ho ditolak, yang berarti ada hubungan yang bermakna secara statistik antara kedua variabel tersebut.

Tabel 5.2 Analisis Hubungan antara Lingkar Lengan Atas dengan Berat Badan Lahir Bayi di

Rumah Sakit Umum Cut meutia Kabupaten Aceh Utara dan Rumah Sakit Tk IV IM.07.01 Lhokseumawe Tahun 2015

\begin{tabular}{llllll}
\hline \multirow{2}{*}{ Lingkar Lengan Atas Ibu } & \multicolumn{3}{c}{ Berat Badan Lahir Bayi } & \multirow{2}{*}{ Total } & \multirow{2}{*}{ p value } \\
\cline { 2 - 4 } Hamil & \multicolumn{1}{c}{ BBLR } & \multicolumn{1}{c}{ Normal } & \multicolumn{1}{c}{ Lebih } & & \\
\cline { 1 - 4 } Bukan Risiko KEKE $(\geq 23,5 \mathrm{~cm})$ & $5(6,4 \%)$ & $70(89,7 \%)$ & $3(3,8 \%)$ & $78(100 \%)$ & \multirow{2}{*}{0,006} \\
Risiko KEK $(<23,5 \mathrm{~cm})$ & $3(42,9 \%)$ & $4(57,1 \%)$ & $0(0 \%)$ & $7(100 \%)$ & \\
\cline { 1 - 4 } Total & $8(9,4 \%)$ & $74(87,1 \%)$ & $3(3,5 \%)$ & $85(100 \%)$ & \\
\hline
\end{tabular}

Sumber: Data primer, 2015

\section{Pembahasan}

Sebagian besar ibu yang melahirkan di Rumah Sakit Umum Cut Meutia Kabupaten Aceh Utara dan Rumah Sakit Tk IV IM.07.01 Lhokseumawe memiliki ukuran lingkar lengan atas (LILA) yang normal dan sebagian kecil memiliki ukuran LILA yang kurang. Hal ini dapat dijelaskan, bahwa masih ada ibu yang memiliki status gizi kurang atau mengalami kurang energi kronis (KEK) pada saat hamil dilihat dari ukuran LILA. Lingkar lengan atas merupakan indikator status gizi yang digunakan terutama untuk deteksi kurang energi protein pada anak-anak dan merupakan indikator yang baik untuk mendeteksi wanita usia subur dan ibu hamil dengan risiko melahirkan bayi dengan berat badan lahir rendah. ${ }^{9}$
Pengukuran LILA lebih baik untuk menilai status gizi ibu hamil, karena pada wanita hamil dengan malnutrisi (gizi kurang atau lebih) kadang-kadang menunjukkan edema tetapi ini jarang mengenai lengan atas. ${ }^{10}$ Kurang energi kronis (KEK) adalah suatu kondisi kurang gizi disebabkan rendahnya konsumsi energi dalam makanan sehari-hari yang berlangsung menahun sehingga tidak memenuhi angka kecukupan gizi. ${ }^{11}$ Dampak kumulatif terhadap status kesehatan dan gizi wanita usia reproduksi merupakan akibat asupan zat gizi yang tidak optimal pada saat bayi sampai masapubertas. ${ }^{2}$ Kehamilan merupakan masa yang penting karena masa ini mempengaruhi kualitas anak yang akan dilahirkan. ${ }^{12}$ Kehamilan menyebabkan meningkatnya metabolisme energi, karena itu kebutuhan energi dan gizi 
lainnya meningkat selama kehamilan. Peningkatan energi dan zat gizi tersebut diperlukan untuk pertumbuhan dan perkembangan janin, pertambahan besarnya organ kandungan, perubahan komposisi dan metabolisme tubuh ibu, sehingga kekurangan zat gizi tertentu yang diperlukan saat hamil dapat menyebakan janin tumbuh tidak sempurna. ${ }^{13}$

Sebagian besar bayi mempunyai berat badan lahir normal pada penelitian ini. Berat badan lahir bayi merupakan cerminan dari status kesehatan dan gizi ibu selama hamil serta pelayanan antenatal yang diterima ibu. ${ }^{14}$ Ibu yang hamil dengan kondisi yang normal, tidak sering menderita sakit dan tidak ada gangguan gizi pada masa pra hamil maupun saat hamil pada umumnya akan melahirkan bayi yang sehat. ${ }^{15}$

Kejadian BBLR pada ibu dengan LILA $<23,5 \mathrm{~cm}$ lebih besar yaitu $42,9 \%$ dibanding ibu dengan LILA normal $(>23,5 \mathrm{~cm})$ yaitu $6,4 \%$. Ibu yang bukan risiko KEK dan ibu yang risiko KEK pada umumnya melahirkan bayi berat badan normal. Lingkar lengan atas ibu hamil sangat mempengaruhi kesempurnaan perkembangan janin selama dalam kandungannya, tetapi belum tentu semua ibu hamil yang mengalami KEK (LLA < 23,5) selalu melahirkan bayi berat lahir rendah (BBLR), karena banyak faktor yang mempengaruhi kelahiran BBLR. Hal ini karena banyak faktor lain yang mempengaruhi berat badan lahir bayi, seperti dari faktor internal ibu yaitu: usia ibu hamil, jarak kehamilan dan kelahiran, paritas, kadar hemoglobin, pemeriksaan kehamilan, penyakit saat kehamilan. Faktor eksternal seperti: faktor lingkungan meliputi kebersihan dan kesehatan lingkungan tempat tinggal, faktor sosial dan ekonomi meliputi jenis pekerjaan, tingkat pendidikan dan pengetahuan ibu hamil. Perlu penelitian lebih lanjut mengenai faktor-faktor lain yang mempengaruhi berat badan lahir bayi.
Berdasarkan uji statistik Chi-Square dan convidende interval 95\% (derajat kemaknaan $0,05)$ yang telah dilakukan, diperoleh nilai signifikansi dari hubungan kedua variabel tersebut adalah $p$ value $=0,006$ sehingga nilai $p$ value $<0,05$, maka Ha diterima. Ini berarti terdapat hubungan antara lingkar lengan atas ibu hamil dengan berat badan lahir bayi. Lingkar lengan atas hanya dapat digunakan untuk kebutuhan screening dalam mengidentifikasi wanita hamil yang berisiko tinggi melahirkan bayi BBLR. Screening bermanfaat dalam program gizi dan kesehatan misalnya dalam menentukan wanita hamil yang perlu mendapatkan PMT (pemberian makanan tambahan) atau membutuhkan penyuluhan, pengobatan atau lainnya selama periode kehamilan, namun tidak disarankan untuk digunakan dalam mengevaluasi hasil intervensi. ${ }^{4}$

\section{Kesimpulan dan Saran}

Hasil pengukuran lingkar lengan atas ibu hamil memiliki ukuran LILA normal yaitu sebanyak 78 orang $(91,8 \%)$ dan 7 orang $(8,2 \%)$ yang memiliki LILA $<23,5 \mathrm{~cm}$ atau berisiko KEK. Berat badan bayi normal yaitu sebanyak 74 bayi $(87,1 \%)$. Bayi berat lahir rendah (BBLR) sebanyak 8 bayi $(9,4 \%)$. Hasil analisis uji statistik Chi-Square menunjukkan terdapat hubungan yang bermakna antara lingkar lengan atas ibu hamil dengan berat badan lahir bayi dengan nilai signifikansi dari hubungan kedua variabel tersebut adalah $p$ value $=0,006$.

Setiap WUS dianjurkan untuk melakukan prenatal conseling sehingga mendapatkan pemahaman tentang asupan nutrisi yang penting untuk mempersiapkan kehamilan dan selama kehamilan. Ibu hamil dengan LILA $<23,5 \mathrm{~cm}$ dengan atau tanpa komplikasi obstetrik dan medik harus diberikan penyuluhan dan pemberian makanan tambahan maupun suplemen agar kejadian BBLR dapat dicegah sedini mungkin. 


\section{Daftar Pustaka}

1. Arisman MB. Gizi ibu hamil, dalam buku ajar ilmu gizi: gizi dalam daur kehidupan, edisi 2. Jakarta: EGC, 2009.

2. Departemen Gizi \& Kesehatan Masyarakat UI. Gizi dan kesehatan masyarakat. edisi 7. Jakarta: PT. Rajagrafindo Persada, 2012.

3. Depkes RI. Profil kesehatan Indonesia 2008. Jakarta: Depkes RI , 2009.

4. Siagian L. Hubungan lingkar lengan atas Hubungan lingkar lengan atas ibu hamil dengan berat bayi lahir di Puskesmas Sigumpar Kabupaten Tobasamosir. Departemen Obstetri dan Ginekologi FK USU Medan, 2010.

5. Assefa N, Berhane Y, Worku A. Wealth status, mid upper arm circumference (MUAC) and antenatal care (ANC) are determinants for low birth weight in Kersa Ethiopia. Jurnal Determinants of low birth weight in Ethiopia. Ababa University Ethiopia 7:6, 2012.

6. Badan penelitian \& pengembangan kesehatan Kemenkes RI. Riset kesehatan Dasar 2010. Jakarta, 2010.

7. Dinkes Aceh Utara. Kematian maternal dan neonatal. Kasi Kesehatan Ibu dan Anak. Lhoksukon, 2014.

8. Dinkes kota Lhokseumawe. Kematian maternal dan neonatal dalam Rekapitulasi PWS KIA. lamp. 4 oleh D Andirani. pengelola program KIA. Lhokseumawe, 2013.
9. Waspadji. Pengkajian status gizi, studi epidemiologi pusat diabetes dan lipid RSCM dan instalasi gizi RSCM. Jakarta: Balai penerbit FKUI, 2011.

10. Ferial EW. Hubungan antara status gizi ibu berdasarkan ukuran lingkar lengan atas (LILA) dengan berat badan lahir bayi di RSUD Daya kota Makassar. Jurnal Alam dan Lingkungan UNHAS 2011;2.

11. Supariasa IDN, Bakri B, Fajar I. Penilaian status gizi. Jakarta: Buku Kedokteran EGC, 2002.

12. Paath EF, Rumdasih, Heriati. Gizi dalam kesehatan reproduksi. Jakarta: EGC, 2005.

13. Lubis Z. Status Gizi Ibu Hamil Serta Pengaruhnya Terhadap Bayi yang Dilahirkan. Program Pascasarjana Institut Pertanian Bogor, 2003.

14. Kusumawati MY. Hubungan Pendidikan dan Pengetahuan Gizi Ibu dengan Berat Bayi Lahir di RSUD DR. Moewadi Surakarta, 2004.

15. Dwi CN. Faktor yang mempengaruhi status gizi ibu hamil di unit rawat jalan hamil instalasi rawat jalan rumah sakit umum dr. Soetomo Surabaya, 2005. 